\title{
ANALISIS PENERAPAN SISTEM MANAJEMEN KESELAMATAN DAN KESEHATAN KERJA (SMK3) DALAM PROYEK PEMBANGUNAN PELABUHAN DI KABUPATEN KENDAL
}

\author{
Prayogo Pandhu $\mathbf{W}^{1}$, Galih Malik Dwi ${ }^{2}$, Bambang Tutuko ${ }^{3}$ \\ ${ }^{1}$ Fakultas Teknik Jurusan Teknik Sipil Universitas Semarang \\ ${ }^{2}$ Fakultas Teknik Jurusan Teknik Sipil Universitas Semarang \\ ${ }^{3}$ Fakultas Teknik Jurusan Teknik Sipil Universitas Semarang
}

\begin{abstract}
ABSTRAK: Di dalam suatu proyek pembangunan, kesehatan keselamatan kerja masing-masing individu sangat berpengaruh terhadap kinerja dalam proyek pembangunan, berdasarkan Pusat Data dan Informasi Ketenagakerjaan Republik Indonesia Tahun 2015, jumlah kecelakaan kerja yang terjadi di Jawa Tengah sebanyak 3.080 kasus kecelakaan kerja. Proyek pembangunan pelabuhan di Kabupaten Kendal dengan potensi bahaya yang cukup tinggi sangat mungkin untuk menimbulkan kecelakaan ataupun kerugian bagi proyek pembangunan tersebut. Untuk mengurangi tingkat kecelakaan kerja perlu adanya sistem manejemen keselamatan dan kesehatan kerja (SMK3) untuk menciptakan keselamatan dan kesehatan kerja bagi pekerja dengan harapan terciptanya lingkungan kerja yang aman, efesien dan produktif.
\end{abstract}

Kata kunci: Kesehatan dan Keselamatan Kerja, kecelakaan Kerja, Sistem Manajemen K3

ABSTRACT: In a construction project, Occupational health and safety each - each individual affects the performance of the construction project, according to the Center for Data and Information of the Republic of Indonesia Year 2015 Labor, the number of occupational accidents that occurred in Central Java as many as 3,080 cases of work accidents. Port construction project in Kendal with a high enough potential hazards is very likely to cause accidents or losses for these development projects. To reduce the accident rate necessary to the management system of occupational safety and health (SMK3) to create health and safety for workers in the hope of creating a safe working environment, efficient and productive.

\section{Keywords:}

\section{LATAR BELAKANG}

Pelabuhan merupakan tempat pemberhentian (terminal) kapal setelah melakukan pelayaran.Di pelabuhan ini kapal melakukan berbagai kegiatan seperti menaik-turunkan penumpang, bongkar muat barang, pengisian bahan bakar dan air tawar, melakukan perbaikan, mengisi perbekalan dan sebagainya. Untuk bisa melaksanakan berbagai kegiatan tersebut pelabuhan harus dilengkapi dengan fasilitas seperti pemecah gelombang, dermaga, peralatan tambatan, peralatan bongkar muat barang, gudang-gudang, halaman untuk menimbun barang, perkantoran baik untuk maskapai pelayaran dan pengelolapelabuhan, perlengkapan pengisian bahan bakar dan penyediaan air bersih dan lain sebagainya.

Berdasarkan data proyeksi pertumbuhan arus penumpang PT. Pelindo III Cabang Tanjung Emas tahun 2000-2025, rata-rata pertumbuhan arus penumpang meningkat sebesar 383.672 orang dari tahun 2000 menjadi 441.223 orang pada akhir tahun 2005 dengan angka pertumbuhan rata-rata 5 tahun terakhir adalah sebesar $3 \%$ per tahun. Sehingga dari data tersebut dapat diproyeksikan besarnya arus penumpang pada akhir tahun 2025 adalah sebesar 847.147 orang. Dengan adanya kenaikan tersebut membuka peluang bagi Kabupaten Kendal untuk berperan dalam penyediaan sarana dan prasarana transportasi laut. Pembangunan Pelabuhan Kendal merupakan pilihan yang sangat mungkin untuk mengatasi kepadatan pelabuhan Tanjung Emas Semarang karena letak Kabupaten Kendal dengan Kota Semarang memang saling berdekatan, juga dengan dibangunnya pelabuhan di Kendal kepadatan arus lalu lintas yang melewati jalur pantai utara (pantura) bisa dikurangi. 
Di dalam suatu proyek pembangunan kesehatan keselamatan kerja masing - masing individu sangat berpengaruh terhadap kinerja dalam proyek pembangunan, berdasarkan Pusat Data dan Informasi Ketenagakerjaan Republik Indonesia Tahun 2015, jumlah kecelakaan kerja yang terjadi di Jawa Tengah sebanyak 3.080 kasus kecelakaan kerja

Proyek pembangunan pelabuhan di Kabupaten Kendal dengan potensi bahaya yang cukup tinggi sangat mungkin untuk menimbulkan kecelakaan ataupun kerugian bagi proyek pembangunan tersebut. Untuk mengurangi tingkat kecelakaan kerja perlu adanya sistem manejemen keselamatan dan kesehatan kerja (SMK3) untuk menciptakan keselamatan dan kesehatan kerja bagi pekerja dengan harapan terciptanya lingkungan kerja yang aman, efesien dan produktif.

\section{Rumusan Masalah}

Berdasarkan paparan diatas, dapat dirumuskan permasalahan Tugas Akhir ini adalah sebagai berikut:

1. Apa saja faktor yang mempengaruhi sistem manejemen keselamatan dan kesehatan kerja (SMK3) pada proyek pembangunan pelabuhan di Kabupaten Kendal?

2. Bagaimana tindakan yang akan di lakukan untuk menerapkan Sistem Manejemen Keselamatan dan Kesehatan Kerja (SMK3) pada proyek pembangunana pelabuhan di Kabupaten Kendal?

\section{Batasan Masalah}

1. Penelitian dilakukan di ruang lingkup proyek pembangunan pelabuhan di Kabupaten Kendal.

2. Penelitian dilakukan saat jam kerja proyek.

3. Data yang di ambil secara umum dianggap telah mewakili keadaan lingkungan proyek pembangunan pelabuhan di Kabupaten Kendal.

\section{Tujuan Penelitian}

1. Menganalisis faktor yang mempengaruhi sistem manajemen keselamatan dan kesehatan kerja (SMK3) pada Proyek pembangunan Pelabuhan di Kabupaten Kendal.

2. Mengetahui bagaimana penerapan Sistem sistem manajemen keselamatan dan kesehatan kerja (SMK3) pada proyek pembangunana pelabuhan di Kabupaten Kendal.

3. Mendapatkan solusi untuk menerapkan sistem manajemen keselamatan dan kesehatan kerja (SMK3) pada proyek pembangunana pelabuhan di Kabupaten Kendal.

\section{Manfaat Penelitian}

1. menambah wawasan mengenai penerapansistem manajemen keselamatan dan kesehatan kerja (SMK3) pada suatu proyek konstruksi yang dapat digunakan sebagai wacana akademis untuk penelitian lebih lanjut.

2. Memberi masukan kepeda penyedia jasa kontruksi agar memperhatikan faktor-faktor keselamatan dan kesehatan kerja sebagai bahan pertimbangan dalam penerapan sistem manajemen keselamatan dan kesehatan kerja (SMK3).

3. menambah pengetahuan teoritis tentang penerapan sistem manajemen keselamatan dan kesehatan kerja (SMK3).

\section{TINJAUAN PUSTAKA}

\section{Keselamatan dan Kesehatan Kerja (K3)}

Keselamatan dan Kesehatan Kerja (K3) tidak dapat dipisahkan dengan proses produktivitas baik jasa maupun industri. Perkembangan pembangunan setelah Indonesia merdeka menimbulkan konsekuensi meningkatkan intensitas kerja yang mengakibatkan meningkatnya risiko kecelakaan di lingkungan kerja.(Ramli, 2010).

Dalam Peraturan Perundang-undangan Republik Indonesia No. 1 tahun 1970 pasal 12 tentang Keselamatan Kerja menjelaskan bahwa perusahaan wajib melindungi keselamatan pekerja yaitu dengan memberi penjelasan kepada tenaga kerja tentang kondisi 
dan bahaya tempat kerja, memberikan alat pelindung diri yang harus di terapkan dalam tempat kerja, serta cara dan sikap yang aman dalam melaksanakan pekerjaan. (Suma'mur, 1989: 29).

Undang-Undang Kesehatan No.23 Tahun 1992 bagian 6 tentang Kesehatan Kerja, Pada Pasal 23 berisi:

1) Kesehatan Kerja diselanggarakan untuk mewujudkan produktivitas kerja yang optimal.

2) Kesehatan kerja meliputi perlindungan kesehatan kerja, pencegahan penyakit akibat kerja, dan syarat kesehatan kerja.

3) Setiap tempat kerja wajib menyelengarakan kesehatan kerja.

\section{Kecelakaan Kerja}

Pengertian kecelakaan kerja menurut Hammer (2001) adalah : "Kejadian yang tak terduga dan tidak dirapkan". Tidak terduga karena dibelakang peristiwa tersebut tidak terdapat unsur kesengajaan dalam bentuk perencanaan. Tidak diharapkan karena peristiwa kecelakaan disertai kerugian materiil ataupun penderitaan dari yang paling ringan sampai kepada yang paling fatal"

Kecelakaan dapat mengakibatkan dampak buruk bagi perusahaan maupun pekerja, dampak tersebut dapat mengakibatkan kerugian bagi perusahaan yaitu tidak berjalanannya kegiatan produksi sehingga akan menimbulkan biaya yang lebih besar lagi. Sedangkan bagi pekerja akan mengakibatkan gangguan kesehatan dan juga akan mengakibatkan kematian. Kecelakaan kerja dapat mengakibatkan produktivitas pekerja menurun sehingga pekerja tidak efektif dan efesien dan mengakibatkan tujuan perusahaan terhambat.

\section{Sistem Manajemen Keselamatan dan Kesehatan Kerja (SMK3)}

Bedasarkan Permen Tenaga Kerja RI Tahun 1996 pasal 2, Sistem Manajemen K3 (SMK3) adalah bagian dari sistem manajemen secara keseluruhan meliputi struktur organisasi, perencanaan, tanggung jawab, pelaksanaan, proseur, proses dan sumber daya yang di butuhkan bagi pengembangan kebijakan K3 dalm rangka pengendalian resiko yang berkaitan dengan kegiatan kerja guna terciptanya tempat kerja yang aman, efesien dan produktif melibatkan unsur manajemen, tenaga kerja, kondisi dan lingkungan kerja yang terintegrasi dalam rangka mencegah dan mengurangi kecelakaan dan penyakit akibat kerja serta terciptanya tempat yang aman, efesien dan produktif.

Menurut George R. Terry, Manajemen didefinisikan sebagai suatu proses yang terdiri dari empat tahapan yaitu:

1) Planning (Perencanaan)

Plenning atau Perencanaan adalan proses dan rangkaian kegiatan untuk menetapkan terlebih dahulu tujuan yang diharapkan pada suatu jangka waktu tertentu atau periode waktu yang telah ditetapkan, serta tahapan yang harus dilalui untuk mencapai tujuan tersebut.

2) Organizing (Organisasi)

Organizing atau Organisasi adalah proses dan rangkaian kegiatan dalam pembagian pekerjaan yang direncanakan untuk diselesaikan oleh anggota kelompok pekerjaan, penentuan hubungan pekerjaan yang baik diantara mereka, serta pemeliharaan lingkungan dan fasilitas pekerjan yang pantas.

3) Actuating (Pelaksanaan)

Actuating atau Pelaksanaan adalah tindakan-tindakan yang menyebabkan suatu organisasi menjadi berjalan.

4) Controlling (Pengawasan)

Controlling Atau Pengawasan adalah kegiatan manajer yang mengusahakan agar pekerjaan-pekerjaan terlaksana sesuai dengan rencana yang ditetapkan dan hasil yang dikendaki.

Seperti yang telah diungkapkan dalam Undang-undang No. 1 tahun 1970 ayat 2 bahwa salah satu tujuan pelaksanaan Keselamatan dan Kesesahan Kerja (K3) adalah untuk menciptakan lingkungan dan tempat kerja yang aman, nyaman, sehat, dan penyesuaian antara pekerjaan dengan manusia atau dengan peralatan (man, machine, environment). 


\section{Prinsip Dasar Sistem Manajemen Keselamatan dan Kesehatan Kerja (SMK3)}

Sesuai dengan BAB III pasal 3 Peraturan Mentri Tenaga Kerja No.05/MEN/1996 Prinsip Dasar Sistem Manajemen K3 Terdiri Dari 5 yang di lakukan secara berkesinambungan yaitu:

1) Komitmen dan Kebijakan.

Komitmen adalah tekad, keinginan dan penyertaan tertulis pengusa atau pengurus dalam pelaksaan K3.

2) Perencanaan.

Perencanaan K3 adalah suatu perencanaan guna mencapai keberhasilan penerapan SMK3 dengan saran yang jelas dan diukur. Perencanaan juga memuat tujuan, sasaran dan indicator kinerja yang diterapkan.(Sastrohardiwiryo, 2001).

3) Penerapan.

Dalam mencapai tujuan keselamatan dan kesehatan kerja, perusahaan harus menunjuk personel yang mempunyai kualifikasi yang sesuai dengan sistem yang diterapkan. Adapun kualifikasi yang tercantum dalam Permen No. 9 tahun 2008 adalah sebagai berikut :

1) Sumber Daya, Struktur Organisasi dan Pertanggungjawaban.

2) Kompetensi, Pelatihan dan Kepedulian.

3) Komunikasi, Kertiban dan konsultasi

4) Dokumentasi.

5) Pengendalian operasional.

6) Pengendalian dokumen

7) Kesiagaan dan tangap darurat. (Permen, 2008).

4) Pengukuran dan Evaluasi.

Perusahaan harus memiliki sistem untuk mengukur, memantau dan mengevaluasi kinerja Sistem Manajemen Keselamatan dan Kesehatan Kerja (SMK3) dan hasil dianalisis guna menentukan keberhasilan atau untuk melakukan identifikasi tindakan perbaikan seperti yang terdapat ada pasal 10 Permen PU tahun 2008 menyatakan bahwa dalam hal materi penyelengaraan Sistem Manajemen Keselamatan dan Kesehatan Kerja (SMK3) kontruksi bidang Pekerjaan Umum yang dijadikan salah satu evaluasi dalam proses pemilihan penyedia jasa, maka Pejabat Pembuat Komitmen (PPK) wajib menyediakan acuannya. Pembuat Komitmen (PPK) ialah pejabat yang melakukan tindakan yang mengakibkan pengeluaran anggaran belanja.

5) Tinjauan Ulang.

Tinjauan ulang pelaksanaan Sistem Manajemen Keselamatan dan Kesehatan Kerja (SMK3) secara berkala untuk menjamin keseuaian dan keefektifitas yang berkesinambungan dalam pencapaian kebijakan dan tujuan Keselamatan dan Kesehatan Kerja (K3). Ruang lingkup tinjauan ulang Sistem Manajemen Keselamatan dan Kesehatan Kerja (SMK3) harus dapat mengatasi inplikasi Keselamatan dan Kesehatan Kerja (K3) terhadap seluruh kegiatan, produk barang dan jasa termasuk dampaknya terhadap kinerja perusahaan. (Sastrohardiwiryo, 2001)

\section{Alat Pelindung Diri}

Alat Pelindung diri adalah semua peralatan termasuk pakaian sandang yang mampu melindungi dari kondisi cuaca, dimana harus dipakai oleh setiap orang pada saat bekerja untuk melindungi dan menghindari dari risiko terhadap Keselamatan dan Kesehatan Kerja. Alat pelindung diri (APD) tidak termasuk dalam pakaian kerja yang lazim seperti seragam yang tidak dikhususkan untuk melindungi keselamatan dan kesehatan, dan tidak digunakan untuk peralatan yang berhubungan dengan persaingan dalam olahraga. (University of St. Andrews. 200:2)

Untuk mencegah kecelakaan pada prinsipnya perlu menghilangkan faktor-faktor berbahaya dengan memperbaiki mesin atau rekayasa engineering dan sarana serta mengubah metode kerja. Pengunaan alat pelindung diri adalah sebagai pendukung bila tidak dapat memperbaiki atau mengganti faktor-faktor yang berbahaya. APD tidak berfungsi untuk menghilangkan risiko bahaya tetapi hanya mengurangi efek atau tingkat keparahan 
dari suatu bahaya dilingkungan kerja. Maka pengunaan APD bersifat hanya sementara dan merupakan suatu alternative terakhir.

\section{METODE PENELITAN}

\section{Pengumpulan Data}

Data yang digunakan dalam Tugas Akhir (TA) ini adalah data primer, yaitu sejumlah data yang diperoleh dari keterangan atau fakta yang secara langsung melalui penelitian dilapangan dari para sumber pertama. Dalam hal ini adalah data yang didapatkan dari para pekerja dan semua pihak yang berada pada lokasi pembangunan pelabuhan di Kabupaten Kendal. Data primer yang dibutuhkan yaitu tanggapan atau pendapat penyelenggara jasa konstruksi mengenai faktor yang mempengaruhi keberhasilan sistem manajemen kesehatan dan keselamatan kerja (SMK3) pada pelaksanaan pembangunan pelabuhan dikabupaten Kendal.

\section{Pelaksanaan Penelitian}

1. Observas/ pengamatan dilapangan.

2. Pembagian kuisioner pada responden.

3. Melakukan studi kepustakaan.

4. Analisis Data.

5. Laporan/ dokumentasi.

\section{Pelaksanaan Penelitian}

\section{Metode Penelitian}

Alur Metode Penelitian mengenai "Analisis Penerapan Sistem Manajemen Keselamatan dan Kesehatan Kerja (SMK3) pada Proyek Pembangunan Pelabuhan di Kabupaten Kendal, pada alir berikut ini:

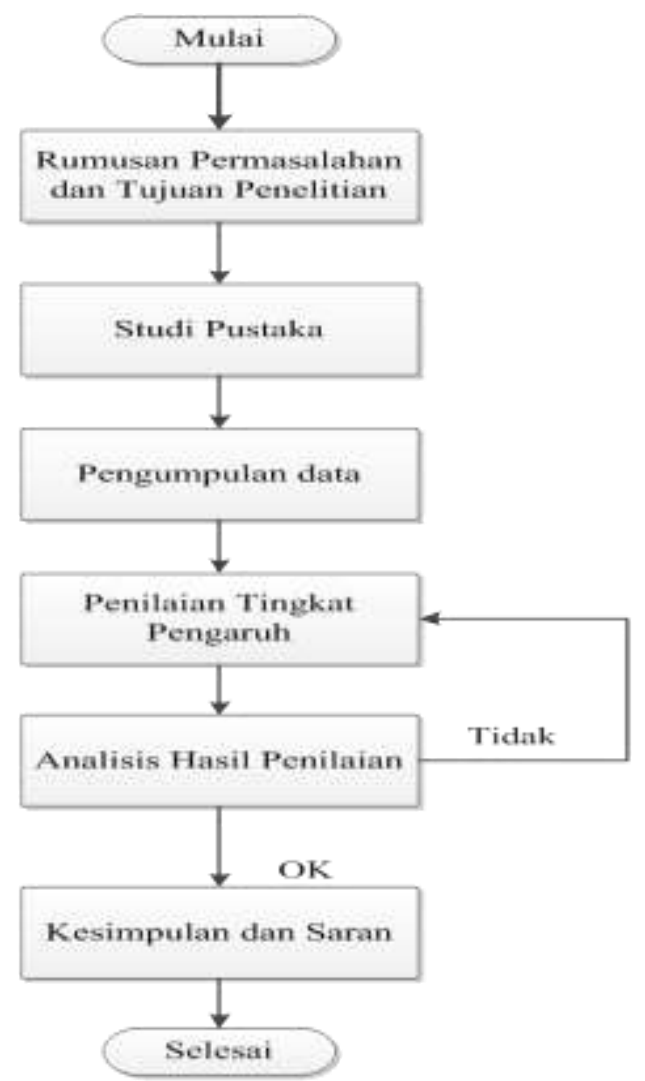

Gambar 1. Diagram Metode Penelitian 


\section{HASIL DAN PEMBAHASAN}

Dari hasil analisis penerapan sistem manajeman K3 pada proyek pembangunan pelabuhan di Kabupaten Kendal, dapat diberikan kesimpulan bahwa penerapan sistem manajemen keselamatan dan kesehatan kerja mempunyai peran yang penting dalam pelaksanaan suatu proyek kontruksi dan pembahasannya antara lain sebagai berikut :

1. Pada fungsi manajemen(planing, organizing, actuating, dan controlling) terkait dengan analisa faktor-faktor yang mempengaruhi penerapan sistem manajemen K3 pada proyek pembangunan pelabuhan di Kabupaten Kendal. Secara rinci fungsi yang paling berpengaruh terhadap analisa ini adalah sebagai berikut

a. Fungsi Perencanaan (Planing)

Pada fungsi perencanaan (planning) faktor yang paling berpengaruh adalah "Pengaturan tempat agar tidak terlalu sempit" pengaturan tempat menjadi faktor yang sangat berpengaruh didalam penerapan sistem manajemen $\mathrm{K} 3$, karena pengaturan tempat yang terlalu sempit dapat menimbulkan risiko terjadi kecelakan kerja dan menghambat proses pembangaunan suatu proyek. Maka dengan pertimbangan hal tersebut, sebuah perusahaan jasa kontruksi perlu memperhatikan pengaturan tempat agar tidak terlalu sempit dan tidak membatasi kinerja dari pekerja.

b. Fungsi Organisasi (Organizing)

Pada Fungsi organisasi (organizing) faktor yang paling berpengaruh adalah "Kurangnya sanksi/denda kepada setiap pekerja yang melanggar dan "Kurangnya komunikasi antar seluruh personil adalah sesuatu yang terpenting dan bernilai". Komunikasi adalah hal yang paling mendasar dari setiap pekerjaan tanpa komunikasi suatu manajemen tidak akan berjalan dengan baik dan diberikannya sanksi tegas bukannya untuk memberatkan para pekerja tetapi supaya mengutamakan keselamatan dan kesehatan setiap individu masing-masing. Oleh karena itu kurangnya komunikasi dan sanksi akan berdampak buruk bagi suatu perkerjaan kontruksi.

c. Fungsi Pelaksanaan (Actuating)

Sedangkan pada fungsi pelaksanaan (actuating) faktor yang paling berpengaruh adalah "Mengutamakan Kesehatan Para Pekerja". Didalam sebuah proyek kontruksi mengutamakan kesehatan para pekerja sangat lah penting, agar pekerja dapat bekerja secara maksimal dan tetap focus didalam pekerjaanya. Maka dari itu para usaha jasa konstruksi harus menjamin kesehatan para pekerjanya karena sangat mendorong produktifitas serta ketenangan kerja pada pegawai.

d. Fungsi Pengawasan (Controlling)

Selanjutnya pada fungsi pengawasan (controlling) faktor yang paling berpengaruh adalah "Pengawasan terhadap resiko kecelakaan kerja". Begitu banyak kecelakaan kerja yang terjadi, pengawasan sangat lah penting bukan dari individunya saja tetapi juga dari perusahaan yang tidak memenuhi standart keselamatan dan kesehatan kerja. Oleh karena itu perlu ditingkatkan pengawasan terhadap resiko kecelakaan kerja. Tidak hanya bagi para pekerja, tetapi juga pengusaha itu sendiri, masyarakat dan lingkungan sehingga terhindar terjadinya kecelakaan kerja.

e. Dari semua pernyataan faktor yang sangat berpengaruh dalam penerapan sistem kesehatan dan keselamatan kerja (K3) adalah kesehatan para pekerja berpengaruh terhadap kinerja suatu pekerjaan, Adanya alat pelindung diri dan P3K, Adanya sosialisasi tentang pentingnya K3.

f. Dalam 4 fungsi manajemen tersebut fungsi pelaksanaan sangatlah berpengaruh besar dalam sistem penerpan kesehatan dan keselamatan kerja (K3).

2. Pada fungsi manajemen(planing, organizing, actuating, dan controlling) terkait dengan analisa tindakan-tindakan yang digunakan untuk penerapan sistem manajemen K3 pada proyek pembangunan pelabuhan di Kabupaten Kendal. Secara rinci fungsi yang paling berpengaruh terhadap analisa ini adalah sebagai berikut :

a. Fungsi Perencanaan (planning) 
Pada fungsi perencanaan (planning) tindakan yang paling berpengaruh adalah "Membuat rencana kerapian penempatan alat-alat kerja". Kerapian merupakan tindakan yang sangat penting karena dengan kerapian penempatan alat kerja akan mengurangi resiko-resiko terjadinya kecelakaan kerja dengan harapan pula para pekerja akan terdidik akan kedisplinan untuk merapikan dan mengembalikan ketempat semula mereka mengambil alat-alat tersebut.

b. Fungsi Organisasi (Organizing)

Pada Fungsi organisasi (organizing) tindakan yang paling berpengaruh adalah "Mengadakan pelatihan khusus dalam masing-masing pekerjaan". Sebagai penyedia jasa konstruksi mengadakan pelatihan khusus dalam masing-masing pekerja nantinya sangat membantu dalam manajemen perkerjaan itu sendiri karena para pekerja sudah cukup tau cara dan resiko dalam setiap masing-masing pekerjaan berbeda. Sehingga menekan angka risiko-risiko kecelakaan kerja yang ditimbulkan dari masing-masing pekerjaan itu sendiri.

c. Fungsi Pelaksanaan (Actuating)

Sedangkan pada fungsi pelaksanaan (actuating) faktor yang paling berpengaruh adalah "Memberikan sosialisasi terhadap pentingnya K3". Pentingnya mensosialisasi kepada para pekerja akan pentingnya keselamatan dan kesehatan kerja karena biasanya para pekerja tidak tahu menahu tetang pentingnya keselamatan dan kesehatan kerja sehingga para pekerja pun tidak memperdulikan itu semua. Oleh karena itu untuk para jasa konstruksi harus sering dilakukan sosisali mengenai K3 tersebut.

d. Fungsi Pengawasan (Controlling)

Selanjutnya pada fungsi pengawasan (controlling) tindakan yang paling berpengaruh adalah" Mengawasi penggunaan dan alat pelindung diri dan Memantau kecelakaan, insiden dan sakit secara kualitif dan kuantitatif ". kedua tindakan tersebut paling banyak dilakukan, karena biasanya dilapangan sering terjadi ketidakdisplinnya para pekerja untuk menggunankan alat pelindung diri dan sering terjadi kecelakaan kerja yang sama. Oleh karena itu tindakan tersebut sangatlah penting agar tidak terjadi halhal yang sama terulang kembali.

e. Dari semua pernyataan tindakan yang sangat berpengaruh dalam penerapan sistem kesehatan dan keselamatan kerja (K3) adalah Memberikan sosialisasi terhadap pentingnya K3, Menyediakan alat pelindung/pengamanan diri, Memberikan pelatihan dan pemberitahuan yang dirancang untuk menanamkan kebiasaan berhati-hati oleh para pekerja.

f. Dalam 4 fungsi manajemen tersebut fungsi pelaksanaan sangatlah berpengaruh besar dalam sistem penerpan kesehatan dan keselamatan kerja (K3).

\section{SARAN}

1. Dalam menentukan pengaturan tempat agar tidak terlalu sempit perusahan jasa konstruksi juga harus memperhatikan jarak tempuh pekerjaan agar tidak memperlambat pekerjaan dan bisa selesai sesuai rencana.

2. Di berikannya sangki/ denda pada setiap pekerja yang melanggar peraturan, dari pihak jasa konstruksi juga harus memberikan penghargaan/hadiah bagi setiap pekerja yang menaati dan displin dari setiap peraturan yang ada.

3. Adanya pelatihan yang berkaitan dengan pekerjaan sangat diperlukannya untuk meningkatkan kualitas para pekerja. Sehingga kedepan perusahaan mempunyai pekerja yang handal dan profesional serta mampu bersaing dengan perusahaan lain.

\section{DAFTAR PUSTAKA}

Ridley J. 2004. Kesehatan dan Keselamatan Kerja, Erlangga, Jakarta.

Ramli, S. 2010. Sistem Manajemen Keselamatan Keseatan Kerja, OHSAS 18001, Dian Rakyat, Jakarta.

Hammer, Wille, 2001. Occupational Safty Management and Engineering, 5 th ed, Prentice Hall. 
Peraturan Mentri Tenaga Kerja No.05/Men/1996 tentang Sistem Manajemen Kesehatan dan Keselamatan Kerja.

Sum'mur, P.K. (1981). Keselamatan dan Pencegahan kecelakaan. Jakarta :CV. Haji Masagung.

Republik Indonesia. (1970). Undang-undang No.1 tahun 1970 tentang Keselamatan Kerja. Jakarta.

Undang-Undang Kesehatan No.23 Tahun1992 bagian 6 Pasal 23, tentang Kesehatan Kerja.

Undang-undang No.13 tahun 2003 pasal 87, tentang ketenaga kerjaan

Peraturan Mentri Tenaga Kerja RI Tahun 1996 pasal 2.

Arikunto, Suharismi. Prosedur Penelitian Suatu Pendekatam Praktek, Rineka Cipta Jakarta.

Satrohardiwiryo, S. (2001). Manajemen Tenaga Kerja Indonesia. PT.bumi Aksara: Bandung.

Djarwanto. 1994. Populasi dan Sampel. Jakarta : Erlangga.

Marzuki. 1995. Sasaran atau Tujuan Penelitian. Jakarta.

Nazir, M. 1985. Metode Penelitian. Ghalia Indonesia.

George R. Terry ,2000. Prinsip-Prinsip Manajemen. (edisi bahasa Indonesia). PT.bumi Aksara: Bandung. 